\title{
New Insight into Effects of $\beta$-Blockers on Arterial Functions
}

\author{
Kazuo Eguchi \\ Division of Cardiovascular Medicine, Department of Medicine, Jichi Medical University, \\ Shimotsuke, Japan
}

\section{Key Words}

Celiprolol $\cdot$ Bisoprolol $\cdot$ Home blood pressure $\cdot$ Ambulatory blood pressure $\cdot$ Flow-mediated vasodilation $\cdot$ Central blood pressure $\cdot$ Pulse wave velocity · Urinary albumin excretion ratio

\begin{abstract}
The effects of $\beta$-blockers on arterial properties are not well investigated. In our recent study, we compared the effects of the two $\beta$-blockers celiprolol and bisoprolol on blood pressure, baroreflex sensitivity (BRS), flow-mediated vasodilatation, and vascular stiffness. We found that bisoprolol achieved a greater reduction in the pulse rate and improved BRS and vascular stiffness, whereas celiprolol reduced the central blood pressure level. In this review, the mechanisms of different types of $\beta$-blockers and their effects on arteries are discussed, and the appropriate use of $\beta$-blockers in hypertensive subjects will be proposed.
\end{abstract}

(C) 2016 S. Karger AG, Basel

\section{Introduction}

In hypertension guidelines, $\beta$-blockers are not recommended for hypertensive subjects unless they have some comorbidities such as ischemic heart disease, heart failure, and other compelling indications [1]. $\beta$-Blockers have even been shown to be harmful for hypertensive subjects [2]. However, the $\beta$-blockers used in these studies were mainly atenolol or metoprolol, and new-generation drugs were not well investigated. In our recent study, we focused on the effects of the new-generation $\beta$-blockers bisoprolol and celiprolol on vascular func-

University Hospital Medical Information Network Clinical Trials Registry (UMIN-CTR): trial No. UMIN000008913. 
tions. Contrary to our expectations, bisoprolol reduced pulse wave velocity (PWV) compared to the baseline, achieved a greater reduction in the pulse rate (PR), and improved baroreflex sensitivity (BRS). On the other hand, celiprolol reduced the central blood pressure (BP) level [3]. Both drugs reduced home and 24-hour BP levels to a similar extent. In that study, we concluded that in treated hypertensive patients, an add-on use of celiprolol may be favorable in an uncomplicated stage of hypertension, whereas bisoprolol may be useful in hypertensive patients with cardiac or vascular diseases who have advanced atherosclerotic changes and sympathetic nervous system activation. In this review, more detailed mechanisms of $\beta$-blockers and their effects on BP and on arteries will be discussed.

\section{$\beta$-Blockers for BP and PR}

Except for compelling indications, $\beta$-blockers are placed as the 4 th or 5 th choice of therapy in the treatment of hypertension [1]. The antihypertensive effects of $\beta$-blockers are not very potent, but sympathetically activated conditions such as hypertensive emergencies, aortic dissection, and high cardiac output states are good indications for $\beta$-blockers [4]. In our study, although the subjects were not suffering from these conditions, both home and ambulatory BP levels were lowered [3]. It could be speculated that this was due to the vasodilating effect and the inhibition of the sympathetic nervous system in celiprolol, and to the potent inhibition of the sympathetic nervous system and an improvement in BRS in bisoprolol.

\section{$\beta$-Blockers for PWV}

There have been several studies which looked at the effects of $\beta$-blockers on PWV $[5,6]$. Asmar et al. [5] showed that the antihypertensive effect of a $\beta 1$ blockade was associated with an improvement in the viscoelastic properties of the brachial artery wall. Hayek et al. [6] showed that the effect of $\beta$-blockers on PWV was significant for the vasodilating $\beta$-blocker nebivolol but not for metoprolol. In our study, the PWV-lowering effect was stronger in the bisoprolol group than in the celiprolol group [3]. These results are somewhat surprising, but they are understandable when considering the effect of bisoprolol on vascular properties. Several $\beta$-blockers have been shown to reduce PWV, except for propranolol and metoprolol [7]. Arterial stiffness is affected by the mean arterial pressure and PR. The higher the PR, the more the artery stiffens, especially in hypertensive patients [8]. Zhou et al. [9] have shown that arterial distensibility and compliance were significantly more improved by bisoprolol therapy than by atenolol therapy, and these effects were independent of any PR-lowering effects. Therefore, the PWV-lowering effect of bisoprolol could be due to its potentPR-lowering effect and to vasodilation caused by $\beta 2$ stimulation benefiting arterial elasticity.

\section{$\beta$-Blockers for Central BP}

Central BP is determined by the reflection waves from the peripheral arteries. It has been shown that $\beta$-blockers are not effective in lowering central BP [10]. In the review by Trudeau et al. [7], $\beta$-blockers were shown to differ with regard to the cardiac afterload. Propranolol and atenolol were not effective in lowering wave reflection, but metoprolol led to a possible improvement, and labetalol, carvedilol, and nebivolol can reduce wave reflection [7]. Zhou et al. [9] showed that bisoprolol had a better effect on central aortic pressure compared to atenolol. 
In our analysis, the radial augmentation index in the bisoprolol group was increased by the reduction in PR as was reported in the studies on atenolol [11-13]. Central systolic BP did not change in the bisoprolol group but was decreased in the celiprolol group. The potent PR-lowering effect of bisoprolol acts to increase central BP, but its vasodilating effect cancels this effect; therefore, central BP is not changed by bisoprolol. The nitric oxide (NO)-dependent pathway in celiprolol therapy could contribute to a reduction in cardiovascular overload by augmented endothelial NO synthase signaling [14]. This is in line with a previous report which found that nebivolol lowered central BP significantly more than metoprolol [15]. The main mechanism for the reduction in central BP in the celiprolol group appeared to involve vasodilation by the NO mechanism and the reverse remodeling of the elastic arteries [16], which led to a reduction in reflection site intensity. Therefore, celiprolol could be better for reducing $\mathrm{PR}$ and central $\mathrm{BP}$ than bisoprolol in hypertensive patients.

\section{$\beta$-Blockers for BRS}

In our analysis, BRS (mean \pm SEM) did not change in the celiprolol group (6.48 \pm 0.52 vs. $6.3 \pm 0.60 \mathrm{~ms} / \mathrm{mm} \mathrm{Hg}, \mathrm{p}=0.69$ ) but was significantly increased in the bisoprolol group (6.95 \pm 0.90 vs. $8.33 \pm 0.94 \mathrm{~ms} / \mathrm{mm} \mathrm{Hg}, \mathrm{p}=0.006$ ) after the treatment [3]. When the differences in BRS between baseline and the 12th week were compared, the extent of increase was significantly greater in the bisoprolol group than in the celiprolol group. The mechanism by which $\beta$-blockers enhance BRS is attributed to an increase in vagal tone [17]. Furthermore, $\beta$-receptor blockade reduces the cardiotoxic effects of endogenous-released catecholamines, inhibits renin release by blocking renal juxtaglomerular cell $\beta 1$ adrenoceptors, blocks presynaptic $\alpha$-adrenoceptor activity by limiting noradrenaline release from sympathetic nerve terminals, and reduces heart rate (HR)-related myocardial oxygen demand [18]. In our study, both HR and BP were lowered with bisoprolol. This may be due to the selective blockade of the $\beta 1$ receptor, but $\beta 2$ receptor-mediated vasodilatation, in skeletal muscles. In addition to the effects on peripheral $\beta 1$-adrenergic receptors, the lipophilic $\beta$-blocker bisoprolol could bind to receptors in the central nervous system. Therefore, a BRS-improving effect was prominent in the bisoprolol group.

\section{$\beta$-Blockers for Flow-Mediated Vasodilatation}

Both drugs significantly improved endothelial function as evaluated by flow-mediated vasodilatation (FMD), and the extent of the improvement was similar [3]. This is in contrast to a previous report which showed that $\beta$-blocker treatment did not modify FMD in the brachial artery [19]. The precise mechanism behind this discrepancy is unclear, but one possible explanation is that it was due to blocking of sympathetic nervous system activity by both drugs. FMD may not be influenced by HR itself, as was shown in a previous study according to which only atenolol changed FMD, even though both drugs achieved similar reductions in PR [20]. In a study on transient endothelial dysfunction due to mental stress, endothelial function was deteriorated by sympathetic nervous system activation [21]. In another study comparing different types of $\beta$-blockers, carvedilol was superior to metoprolol in improving endothelial function [22]. Vasodilating $\beta$-blockers have been shown to improve endothelial functions $[23,24]$. Bisoprolol was also shown to have vasodilating effects due to endothelium-dependent mechanisms [9], while celiprolol is known to have a vasodilating effect by an NO-dependent pathway [14]. The potency of vasodilatation would be similar in celiprolol and bisoprolol because the extent of the improvement in FMD was similar with 
both drugs. Thus, the improvement in endothelial function with celiprolol and bisoprolol may be due to both a vasodilating mechanism and the inhibition of sympathetic nervous system activity, with different proportions of these mechanisms being involved.

\section{Conclusions}

In treated hypertensive patients, celiprolol and bisoprolol, relatively newer $\beta$-blockers, lowered clinic, home, and ambulatory BP levels and improved endothelial functions, but the reduction in central BP was better in the celiprolol treatment group than in the bisoprolol treatment group. Thus, celiprolol would be effective in lowering central BP in hypertensive subjects. In contrast, bisoprolol improved PR, PWV, and BRS, which indicates that bisoprolol is effective in improving sympathetic hyperactivity and stiffened arteries. Based on these findings, the add-on use of celiprolol may be favorable in an uncomplicated stage of hypertension. On the other hand, bisoprolol may be useful in hypertensive patients with cardiac or vascular diseases who have advanced atherosclerotic changes and sympathetic nervous system activation.

\section{Disclosure Statement}

The authors have no conflicts of interest to report.

\section{References}

1 Shimamoto K, Ando K, Fujita T, Hasebe N, Higaki J, Horiuchi M, Imai Y, Imaizumi T, Ishimitsu T, Ito M, Ito S, Itoh H, Iwao H, Kai H, Kario K, Kashihara N, Kawano Y, Kim-Mitsuyama S, Kimura G, Kohara K, Komuro I, Kumagai H, Matsuura H, Miura K, Morishita R, Naruse M, Node K, Ohya Y, Rakugi H, Saito I, Saitoh S, Shimada K, Shimosawa T, Suzuki H, Tamura K, Tanahashi N, Tsuchihashi T, Uchiyama M, Ueda S, Umemura S; Japanese Society of Hypertension Committee for Guidelines for the Management of Hypertension: The Japanese Society of Hypertension Guidelines for the Management of Hypertension (JSH 2014). Hypertens Res 2014;37:253390.

2 De Caterina AR, Leone AM: Why $\beta$-blockers should not be used as first choice in uncomplicated hypertension. Am J Cardiol 2010;105:1433-1438.

3 Eguchi K, Hoshide S, Kario K: Effects of celiprolol and bisoprolol on blood pressure, vascular stiffness, and baroreflex sensitivity. Am J Hypertens 2015;28:858-867.

4 Frishman WH, Saunders E: $\beta$-Adrenergic blockers. J Clin Hypertens (Greenwich) 2011;13:649-653.

5 Asmar RG, Kerihuel JC, Girerd XJ, Safar ME: Effect of bisoprolol on blood pressure and arterial hemodynamics in systemic hypertension. Am J Cardiol 1991;68:61-64.

6 Hayek SS, Poole JC, Neuman R, Morris AA, Khayata M, Kavtaradze N, Topel ML, Binongo JG, Li Q, Jones DP, Waller EK, Quyyumi AA: Differential effects of nebivolol and metoprolol on arterial stiffness, circulating progenitor cells, and oxidative stress. J Am Soc Hypertens 2015;9:206-213.

7 Trudeau L: Central blood pressure as an index of antihypertensive control: determinants and potential value. Can J Cardiol 2014;30:S23-S28.

8 Tan I, Butlin M, Liu YY, Ng K, Avolio AP: Heart rate dependence of aortic pulse wave velocity at different arterial pressures in rats. Hypertension 2012;60:528-533.

9 Zhou W-J, Wang R-Y, Li Y, Chen D-R, Chen E-Z, Zhu D-L, Gao P-J: A randomized controlled study on the effects of bisoprolol and atenolol on sympathetic nervous activity and central aortic pressure in patients with essential hypertension. PLoS One 2013;8:e72102.

10 Williams B, Lacy PS, Thom SM, Cruickshank K, Stanton A, Collier D, Hughes AD, Thurston H, O'Rourke M; CAFE Investigators; Anglo-Scandinavian Cardiac Outcomes Trial Investigators; CAFE Steering Committee and Writing Committee: Differential impact of blood pressure-lowering drugs on central aortic pressure and clinical outcomes: principal results of the Conduit Artery Function Evaluation (CAFE) study. Circulation 2006; 113:1213-1225.

11 Dhakam Z, Yasmin, McEniery CM, Burton T, Brown MJ, Wilkinson IB: A comparison of atenolol and nebivolol in isolated systolic hypertension. J Hypertens 2008;26:351-356. 
Eguchi: New Insight into Effects of $\beta$-Blockers on Arterial Functions

12 Mahmud A, Feely J: $\beta$-Blockers reduce aortic stiffness in hypertension but nebivolol, not atenolol, reduces wave reflection. Am J Hypertens 2008;21:663-667.

13 Mackenzie IS, McEniery CM, Dhakam Z, Brown MJ, Cockcroft JR, Wilkinson IB: Comparison of the effects of antihypertensive agents on central blood pressure and arterial stiffness in isolated systolic hypertension. Hypertension 2009;54:409-413.

14 Liao Y, Asakura M, Takashima S, Ogai A, Asano Y, Shintani Y, Minamino T, Asanuma H, Sanada S, Kim J, Kitamura S, Tomoike H, Hori M, Kitakaze M: Celiprolol, a vasodilatory $\beta$-blocker, inhibits pressure overload-induced cardiac hypertrophy and prevents the transition to heart failure via nitric oxide-dependent mechanisms in mice. Circulation 2004;110:692-699.

15 Kampus P, Serg M, Kals J, Zagura M, Muda P, Karu K, Zilmer M, Eha J: Differential effects of nebivolol and metoprolol on central aortic pressure and left ventricular wall thickness. Hypertension 2011;57:1122-1128.

16 Boutouyrie P, Bussy C, Hayoz D, Hengstler J, Dartois N, Laloux B, Brunner H, Laurent S: Local pulse pressure and regression of arterial wall hypertrophy during long-term antihypertensive treatment. Circulation 2000; 101:2601-2606.

17 Ablad B, Bjurö T, Björkman JA,Edström T: Prevention of ventricular fibrillation requires central $\beta$-adrenoceptor blockade in rabbits. Scand Cardiovasc J 2007;41:221-229.

18 López-Sendó J, Swedberg K, McMurray J, Tamargo J, Maggioni AP, Dargie H, Tendera M, Waagstein F, Kjekshus J, Lechat P, Torp-Pedersen C; Task Force on $\beta$-Blockers of the European Society of Cardiology: Expert consensus document on $\beta$-adrenergic receptor blockers. Eur Heart J 2004;25:1341-1362.

19 Ghiadoni L, Magagna A, Versari D, Kardasz I, Huang Y, Taddei S, Salvetti A: Different effect of antihypertensive drugs on conduit artery endothelial function. Hypertension 2003;41:1281-1286.

20 Nerla R, Di Franco A, Milo M, Pitocco D, Zaccardi F, Tarzia P, Sarullo FM, Villano A, Russo G, Stazi A, Ghirlanda G, Lanza GA, Crea F: Differential effects of heart rate reduction by atenolol or ivabradine on peripheral endothelial function in type 2 diabetic patients. Heart 2012;98:1812-1816.

21 Ghiadoni L, Donald AE, Cropley M, Mullen MJ, Oakley G, Taylor M, O'Connor G, Betteridge J, Klein N, Steptoe A, Deanfield JE: Mental stress induces transient endothelial dysfunction in humans. Circulation 2000;102:24732478.

22 Bank AJ, Kelly AS, Thelen AM, Kaiser DR, Gonzalez-Campoy JM: Effects of carvedilol versus metoprolol on endothelial function and oxidative stress in patients with type 2 diabetes mellitus. Am J Hypertens 2007;20: 777-783.

23 Tzemos N, Lim PO, MacDonald TM: Nebivolol reverses endothelial dysfunction in essential hypertension: a randomized, double-blind, crossover study. Circulation 2001;104:511-514.

24 Kalinowski L, Dobrucki LW, Szczepanska-Konkel M, Jankowski M, Martyniec L, Angielski S, Malinski T: Thirdgeneration $\beta$-blockers stimulate nitric oxide release from endothelial cells through ATP efflux: a novel mechanism for antihypertensive action. Circulation 2003;107:2747-2752. 